\title{
In-kind transfers and home production
}

\author{
Matthew Greenblatt $\mathbb{D}^{1}$
}

Received: 8 February 2020 / Accepted: 7 September 2020 / Published online: 21 September 2020

(c) Springer Science+Business Media, LLC, part of Springer Nature 2020

\begin{abstract}
Why are in-kind transfers a prominent feature of the U.S. social safety net, and why is such a significant fraction of these benefits given to individuals who do not actively supply labor in the market? This paper presents home production as a novel rationalization for such transfers. It first shows that in a broad class of dynamic Mirrleesian models that include only market production, the optimal allocation features undistorted marginal rates of substitution between goods whenever agents are not working, and thus in-kind benefits provided to these agents do not help decentralize an optimal allocation. However, adding home production drastically changes the nature of the optimal allocation. In particular, if goods and labor are substitutes in home production and home and market productivity are positively correlated, in-kind benefits in the form of goods used in home production, such as groceries, energy, and housing capital, should be provided to agents who do not work. A numerical simulation shows that the optimal in-kind program for disabled workers in a plausibly calibrated version of the home production model is consistent with the scale of SNAP and other programs that provide home production goods in the U.S.
\end{abstract}

Keywords Home production $\cdot$ In-kind transfers $\cdot$ Optimal taxationg $\cdot$ Food stamps

JEL Codes D13 $\cdot \mathrm{H} 21 \cdot \mathrm{H} 42$

\section{Introduction}

Government provision of private goods is a prominent feature of welfare programs throughout the developed world. In the U.S., for instance, in 2015, federal government spending on Medicare, Medicaid, SNAP (Food Stamps), and primary and secondary education constituted $10.5 \%$ of GDP according to the United States House of Representatives Ways and Means Committee Green Book. Despite their

Matthew Greenblatt

greenblm@tcnj.edu

1 The College of New Jersey, Ewing, NJ, USA 
prevalence, there has long been skepticism about the value of such in-kind benefits. After all, giving recipients the cash value of the benefits would not restrict their behavior, leading to at least a weak improvement in their welfare.

In response, economists have offered three broad classes of arguments made in favor of in-kind benefits. The first, which follows Loury (1981) and focuses on public provision of education, ${ }^{1}$ argues that in-kind provision of education can be an efficient response to market incompleteness caused by borrowing constraints faced by parents in financing human capital investment for their children. Public education programs can correct inefficiently low levels of educational investment by low income parents and social moblity created by these borrowing constraints. Another, following Musgrave (1959) and many others, contends that in-kind provision is a tool of paternalism. By restricting the behavior of welfare recipients with in-kind benefits, governments are able to effectively prevent them from making choices deemed to be socially undesirable. The third, following Atkinson and Stiglitz (1976) argues that, to the extent to which in-kind benefits make welfare less attractive, providing in-kind benefits allows the government to screen applicants by providing an incentive for those who do not need assistance to pay into the welfare system rather than claiming benefits. This literature shows that, when there are non-separabilities between consumption and leisure, subsidizing some goods relative to others can be an efficient way to incentivize labor supply. In-kind provision is one way to achieve such subsidies.

A documented challenge for the validity of interpreting in-kind provision as a means for efficiently providing incentives is that a significant fraction of these inkind welfare benefits are paid out to households that do not supply labor. In the U.S., for instance, the single largest in-kind program is Medicare, a health insurance program targeted specifically at retirees. Many enrolled in Medicaid, which is targeted at low-income households, are also recipients of long-term disability insurance payments and thus do not work. In $201622 \%$ of all households receiving SNAP benefits had a member at or near retirement age and $20 \%$ had a member on long-term disability. The majority of both groups receiving SNAP benefits ( $82 \%$ for the elderly and $67 \%$ for the disabled) were single heads-of-household, indicating that they were the targeted recipients of the benefits. ${ }^{2}$ In light of these facts, Currie and Gahvari (2008) contend that it is difficult to see the goal of these programs as incentivizing labor supply. This paper addresses the question of whether there is a credible incentive argument for providing in-kind benefits to agents that supply no labor. First, it follows up on Currie and Gahvari's conjecture first by showing that it is correct in the sense that, in a standard Mirrleesian framework, there is no efficiency reason to distort margins between goods when agents do not supply labor, even in the presence of non-separabilities.

However, I then show that by adding home production to the standard Mirrleesian framework there is an efficiency reason for such distortions, even when agents are not working in the market. More specifically, I add a Beckerian home production technology that uses some consumption goods as inputs (such as groceries) but not

\footnotetext{
1 Public education spending represents the second largest category of spending on in-kind benefits in the U.S. after healthcare. It accounted for 5.3\% of GDP in 2015. See Fig. 1 for more details.

${ }^{2}$ Source: https://www.fns.usda.gov/pd/supplemental-nutrition-assistance-program-snap. SNAP benefits are awarded at the household level.
} 


\section{U.S. Government In-Kind Programs as a Percentage of GDP}

(2015)

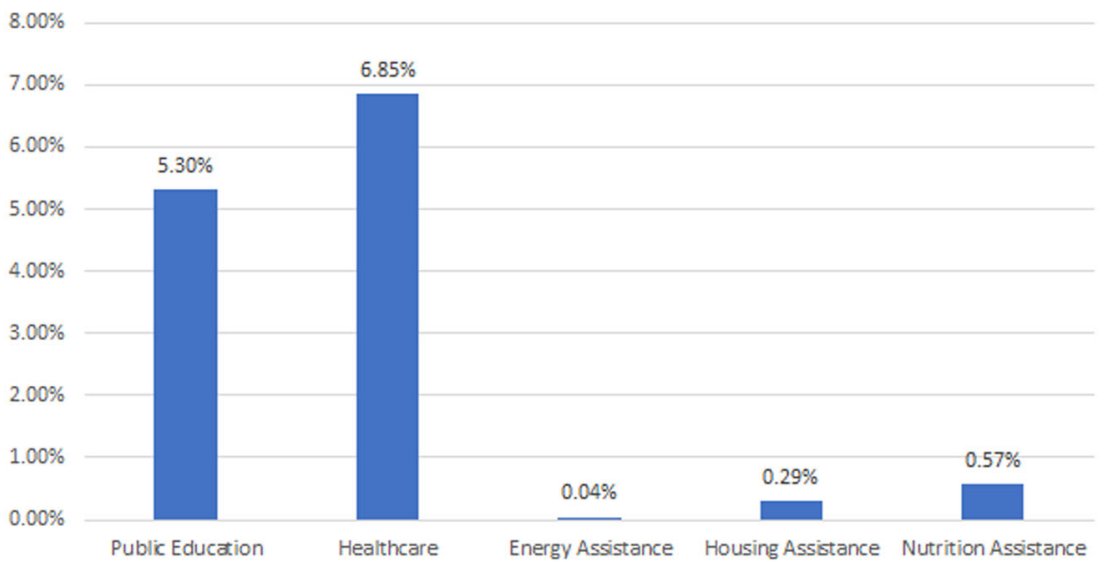

Fig. 1 U.S. Government spending on in-kind programs as a fraction of GDP. In-kind programs are categorized as in the U.S.H.R. Ways and Means Greenbook 2016 edition. Data for Federal programs is obtained from the U.S.H.R. Ways and Means Greenbook 2016 edition, Federal Benefits and Services for People with Low Income Supplement, Table 1. This is combined with data on state and local government spending from the BEA NIPA Tables 3.12 and 3.16. State and local governments constitute the majority of spending on public education and approximately half of health spending (Medicaid spending is attributed to state and local governments in NIPA). Public education includes spending on Job Training Programs, which is small relative to other forms of education spending. Intermediate goods for home production, which are provided in-kind in the model, correspond most closely to the goods provided by energy assistance, hosuing assistance, and nutrition assistance programs. Combined, spending on these programs represents $\sim 0.9 \%$ of U.S. GDP

Table 1 Model parameters for numerical exercise

\begin{tabular}{lll}
\hline Parameter & Value & Source or target \\
\hline$\theta_{2}^{h}$ & 1 & Normalization \\
$\theta_{1}^{h}$ & 1 & Normalization \\
$\theta_{2}^{l}$ & 0.5 & N/A \\
$\theta_{1}^{l}$ & 0 & Low types are disabled \\
$\pi$ & 0.9 & BLS disability data \\
$\gamma$ & 0.4 & McGrattan, Rogerson, and Wright \\
$\sigma$ & 1.45 & Aguiar and Hurst \\
$\alpha$ & 4.67 & Cociuba and Prescott hours data \\
\hline
\end{tabular}

$\theta_{2}^{h}$ is the home productivity of high types. $\theta_{1}^{h}$ is the market productivity of high types. $\theta_{2}^{l}$ is the home productivity of low types. $\theta_{1}^{l}$ is the market productivity of low types, set to zero to capture disability. $\pi$ is the fraction of the population that is high types. $\gamma$ is the factor intensity of goods in home production. $\sigma$ is the elasticity of technical substitution between goods and labor in home production, $\sigma>1$ implies goods are a substitute for labor and should be provided in-kind for low types in an optimal allocation. $\alpha$ is the marginal disutility of working. 
others (such as restaurant meals). The information-constrained efficient allocation will subsidize goods used in home production for low-skill types if goods and labor are substitutes in home production. Such subsidization could be achieved by in-kind provision of goods used intensively in home production. While this argument does not apply to all in-kind benefit programs in the U.S. (for instance, healthcare programs such as Medicare and Medicaid), it is generally consistent with: (1) the fact that many in-kind programs in the U.S. provide goods that are used in home production; ${ }^{3}$ and (2) empirical work (e.g., Aguiar and Hurst 2007) that has found that goods and labor are indeed substitutes in home production. I conduct a numerical experiment with plausible parameters for the home production model and find that the scale of the in-kind program required to implement the constrained efficient allocation is consistent with the design and scale of U.S. programs.

\section{Related literature}

This paper makes a contribution to several strands of literature. First it addresses the debate on paternalism versus incentives as the motivation for in-kind provision, making both a theoretical and empirical contribution. Paternalism has traditionally been modeled as a consumption externality, where the utility that some agents derive from a subset goods, called "merit goods," directly enters the utility function of other agents. Rich agents, for instance, may care about poor agents' consumption of food and medical care, but not their consumption of alcohol and tobacco. In such cases, optimal policy will encourage the consumption of merit goods. This can be achieved by providing merit goods in-kind, as shown by Gasparini and Pinto (2006), König and Lausen (2016), and others. The empirical importance of paternalistic motives is addressed by Mulligan and Philipson (2000). However, their analysis focuses mainly on the in-kind provision of annuities through the U.S. social security program, which is orthogonal to the provision goods for home production.

Multiple literatures have examined the incentives argument. The first, which follows Nichols and Zeckhauser (1982), treats in-kind provision as a way of screening welfare applicants whose income is unknown. The basic argument presented in these papers is that certain goods, called "indicator goods," have a high marginal utility when income is low. In-kind provision of these goods will thus be more valued by the lower income households who are the intended recipients of welfare, making them more likely to apply for benefits. Blackorby and Donaldson (1988), who present a model where the underlying source of income variation is disability status, identify health insurance as an indicator good, as it is more highly valued by lower income households who have greater need of medical care. Besley and Coate (1991) present a model with a discrete good that may be consumed in differing levels of quality, such as schooling. They argue that if quality of the discrete good is normal, a low quality version of the discrete good may be offered universally, such as public schooling. This will effectively act as an indicator good, as higher income households will choose to buy higher quality versions of the discrete good in private markets rather than taking advantage of the publicly

${ }^{3}$ SNAP, for instance, provides groceries and the Section 8 program provides housing. 
provided option, and will thus screen themselves out of the benefit. This argument is expanded on in Pinto (2004) and Gahvari and Mattos (2007). In related work, Loury (1981) and Baland and Robinson (2000) explicitly model these differing valuations of education across income groups as stemming from diminishing returns to investment in human capital and borrowing constraints for financing human capital investment. Both papers find that providing education as an in-kind benefit through a public schooling system can generate Pareto improvements over a laissez-faire outcome. In their models, public education redistributes educational spending to lower income children whose parents are financially constrained in the absence of government intervention and thus face a higher marginal return to educational investment. These theoretical results were investigated recently by Daruich (2020), who found that subsidies for early childhood education meant to ease borrowing constraints for poorer households had quantitatively large positive welfare effects in a simulated economy.

By contrast to the literature examining income screening, I assume that income is observable to the government, and thus there is no direct need to screen out highincome households from receiving welfare benefits. Rather, observable income differences between households are driven by unobservable differences in labor productivity. Because the government wishes to insure agents against these productivity differences through the welfare system, in-kind provision becomes a means to incentivize efficient labor supply conditional on household labor productivity. The issue of in-kind provision in this context was first examined by Guesnerie and Roberts (1984), who showed that imposing quotas on goods that are substitutes for leisure can slacken incentive constraints for high productivity households and free up more resources for redistribution to lower income households. Such goods effectively act as indicator goods as envisioned by Nichols and Zeckhauser (1982). This is because higher income households could earn the same income as lower income households, and thus receive the same welfare benefits, by spending less time working than the lower income household. However, since the welfare benefit takes the form of a good that is a substitute for leisure, the higher income household would value it less. This discourages the higher income household from trying to shave its income to qualify for benefits. Similar arguments can be found in Blomquist and Christiansen (1995), Blomquist and Christiansen (1998), Blomquist and Christiansen (1998), Boadway and Marchand (1995), Cremer and Gahvari (1997), Cremer and Gahvari (1998), and Gahvari (1995), among others.

One assumption in much of this literature is that low productivity households have an interior solution for labor supply in the optimal allocation that the welfare system is attempting to decentralize. This ensures that low-productivity types and highproductivity types that earn low income consume different amounts of leisure and thus goods that are substitutes for leisure will indeed function as indicator goods. This would not be true if low productivity households supply no labor in the optimal allocation, as I show in a stylized model in Section 3 and more generally in the appendix of this paper. This is the core of the criticism of the incentive argument in Currie and Gahvari (2008). However, I show that goods used intensively in home production still function as indicator goods when Beckerian home production is added to the model, even if low productivity households do not supply labor. Thus the MRS between goods used in home production and final market 
consumption goods will be distorted in the optimal allocation, and in-kind provision is justified.

As in-kind welfare benefits subsidize the goods that are provided in-kind, the analysis of in-kind welfare benefits in a Mirleesian setting is also intimately related to the redundancy of differential commodity taxation discussed in Atkinson and Stiglitz (1976) and the literature that follows their work and seeks to establish conditions on preferences and technology when this result holds (see, e.g. Bastani et al. 2015, da Costa 2009, Gahvari and Micheletto 2016, Golosov et al. 2003, and Kaplow 2006). The use of home production as a justification for differential commodity taxation is novel. However, within the context of this literature, my model of home production can be thought of as an example of the type-specific utility function discussed in Saez (2002). The type specificity of the valuation of goods in my model follows from the fact that agents who are more productive in home production may find goods used intensively in home production inherently more or less valuable, depending whether those goods are complements or substitutes for labor in the home production process.

Finally, this paper makes a contribution to the growing literature that integrates home production into macroeconomic models for the purpose of policy analysis. Following the representative agent approach of McGrattan et al. (1997) and Greenwood and Hercowitz (1991), Zhang et al. (2008) and Olovsson (2015) have studied Ramsey taxation and Gnocchi, Hauser and Pappa (2016) study monetary and fiscal multipliers. Following the heterogeneous agent approach of Aguiar and Hurst (2007), Dotsey et al. (2015) studied social security reform and Campos and Reggio (2016) examined optimal unemployment insurance. My paper is the first to consider non-parametric optimal taxation in a model with home production. The remainder of the paper is organized as follows. Section 3 presents a simple Mirleesian model to motivate the undistorted MRS result, which is generalized in the appendix. Section 4 contains the model with home production and the numerical exercise. Section 5 concludes.

\section{A simple Mirrleesian model}

This section develops a two-productivity type, two-good Mirrleesian model to examine when it is optimal for the social planner to distort the consumption margins of the agents. In particular, I will show that, assuming that only the local downward incentive constraint binds, the consumption margins of the high type are never distorted in the optimal allocation. It may be optimal to distort the consumption margins of the low type. However, if the low type does not work, then consumption margins for the low type will not be distorted in the optimal allocation either. Analysis of this simple model provides intuition for the broader result that follows in the appendix. In particular, I will show that the rationale for distorting the consumption margin of low types is to take advantage of differing degrees of complementarity of different goods with leisure. By offering an allocation for low types that "subsidizes" goods that are substitutes for leisure and "taxes" goods that are complements to leisure, the planner can increase the utility 
of honest low types more than the utility of high types claiming to be low types because a dishonest high type consumes more leisure than an honest low type. These distortions will thus slacken the incentive constraint, allowing the planner to provide higher expected utility. However, in the case of an optimal allocation where the low type does not work, the low type and the dishonest high type consume the same amount of leisure and this motivation for distorting the consumption margins disappears.

\subsection{Model}

There is a single time period and a continuum of agents. Each agent receives a productivity type $\theta \in\left\{\theta^{l}, \theta^{h}\right\}$, where $\theta^{h}>\theta^{l}>0$. The probability that an agent is of type $\theta^{l}$ is given by $\pi \in(0,1)$. Productivity types are private information of agents. There is a single final good $y$ which may transformed one for one into two different consumption goods $c_{1}$ and $c_{2}$. An agent of type $\theta$ may transform labor $l$ into a quantity $y$ of the final good according to $y=\theta l$. The labor supply of agents is not publicly observable; however, consumption and output are. Agents have typeindependent preferences over consumption and labor represented by the utility function $U\left(c_{1}, c_{2}, l\right)$. $U$ is assumed to be increasing in $c_{1}$ and $c_{2}$ and decreasing in $l$. Appealing to the revelation principle, substituting labor $l$ for output divided by productivity $\frac{y}{\theta}$ in the utility function, and assuming that only the incentive constraint of the high productivity type is binding, the problem of an information constrained utilitarian social planner in this environment is to choose type-specific consumption and output $c_{1}^{\theta}, c_{2}^{\theta}, y^{\theta}$ to solve

$$
\begin{aligned}
& \max _{c_{1}^{\theta^{l}}, c_{2}^{\theta^{l}}, y^{\theta^{l}}, c_{1}^{\theta^{h}}, c_{2}^{\theta^{h}}, y^{\theta^{h}}} \pi U\left(c_{1}^{\theta^{l}}, c_{2}^{\theta^{l}}, \frac{y^{\theta^{l}}}{\theta^{l}}\right)+(1-\pi) U\left(c_{1}^{\theta^{h}}, c_{2}^{\left.\theta^{\theta^{h}}, \frac{y^{\theta^{h}}}{\theta^{h}}\right)}\right. \\
& \text { s.t. } \pi\left[c_{1}^{\theta^{l}}+c_{2}^{\theta^{l^{l}}}\right]+(1-\pi)\left[c_{1}^{\theta^{h}}+c_{2}^{\theta^{h}}\right]=\pi y^{\theta^{l}}+(1-\pi) y^{\theta^{h}} . \\
& U\left(c_{1}^{\theta^{h}}, c_{2}^{\theta^{h}}, \frac{y^{\theta^{h}}}{\theta^{h}}\right) \geq U\left(c_{1}^{\theta^{l}}, c_{2}^{\theta^{l}}, \frac{y^{\theta^{l}}}{\theta^{h}}\right)
\end{aligned}
$$

The first constraint of this problem is a standard resource constraint. The second is an incentive constraint, which requires that high types prefer to tell the planner that they are high types and consume the allocation of the high type rather than telling the planner they are low types and consuming the allocation of the low type. Let $\lambda$ and $\mu$ denote the Lagrange multipliers on the resource constraint and the incentive constraint, respectively. The first-order conditions for consumption goods $i=1,2$ for low and high $\theta$ types are given by

$$
\begin{gathered}
c_{i}^{\theta^{l}}: \pi U_{c_{i}}\left(c_{1}^{\theta^{l}}, c_{2}^{\theta^{l}}, \frac{y^{\theta^{l}}}{\theta^{l}}\right)-\pi \lambda-\mu U_{c_{i}}\left(c_{1}^{\theta^{l}}, c_{2}^{\theta^{l}}, \frac{y^{\theta^{l}}}{\theta^{h}}\right)=0, \\
c_{i}^{\theta^{h}}: \quad(1-\pi) U_{c_{i}}\left(c_{1}^{\theta^{h}}, c_{2}^{\theta^{h}}, \frac{y^{\theta^{h}}}{\theta^{h}}\right)-(1-\pi) \lambda+\mu U_{c_{i}}\left(c_{1}^{\theta^{h}}, c_{2}^{\theta^{h}}, \frac{y^{\theta^{h}}}{\theta^{h}}\right)=0 .
\end{gathered}
$$


Equations (1) and (2) imply that marginal rates of substitution between goods in the optimal allocation for low and high types will respectively satisfy

$$
\begin{gathered}
\frac{U_{c_{1}}\left(\theta^{l}\right)}{U_{c_{2}}\left(\theta^{l}\right)}=\frac{1-\frac{\mu}{\pi} \frac{U_{c_{2}}\left(c_{1}^{\theta^{l}}, c_{2}^{\theta^{l}}, \frac{y^{\theta^{l}}}{\theta^{h}}\right)}{U_{c_{2}}\left(\theta^{l}\right)}}{1-\frac{\mu}{\pi} \frac{U_{c_{1}}\left(c_{1}^{\theta^{l}}, c_{2}^{\theta^{l}}, \frac{y^{\theta^{l}}}{\theta^{h}}\right)}{U_{c_{1}}\left(\theta^{l}\right)}}, \\
\frac{U_{c_{1}}\left(\theta^{h}\right)}{U_{c_{2}}\left(\theta^{h}\right)}=\frac{1+\frac{\mu}{1-\pi}}{1+\frac{\mu}{1-\pi}}=1 .
\end{gathered}
$$

Here, I use the notation $U_{c_{i}}(\theta)=U_{c_{i}}\left(c_{1}^{\theta}, c_{2}^{\theta}, y^{\theta} / \theta\right)$. It follows from Eq. (4) that the consumption margin of the high type is never distorted in the optimal allocation (the marginal rate of substitution between $c_{1}$ and $c_{2}$ is set equal to the marginal rate of transformation, which in this case is 1). Equation (3) implies that the consumption margins of the low type will be distorted whenever

$$
\frac{U_{c_{1}}\left(\theta^{l}\right)}{U_{c_{2}}\left(\theta^{l}\right)}=\frac{U_{c_{1}}\left(c_{1}^{\theta^{l}}, c_{2}^{\theta^{l}}, \frac{y^{\theta^{l}}}{\theta^{l}}\right)}{U_{c_{2}}\left(c_{1}^{\theta^{l}}, c_{2}^{\theta^{l}}, \frac{y^{\theta^{l}}}{\theta^{l}}\right)} \neq \frac{U_{c_{1}}\left(c_{1}^{\theta^{l}}, c_{2}^{\theta^{l}}, \frac{y^{\theta^{l}}}{\theta^{h}}\right)}{U_{c_{2}}\left(c_{1}^{\theta^{l}}, c_{2}^{\theta^{l}}, \frac{y^{\theta^{l}}}{\theta^{h}}\right)} .
$$

There will be a positive distortion to the consumption margin of the low type whenever

$$
\frac{U_{c_{1}}\left(c_{1}^{\theta^{l}}, c_{2}^{\theta^{l}}, \frac{y^{\theta^{l}}}{\theta^{l}}\right)}{U_{c_{2}}\left(c_{1}^{\theta^{l}}, c_{2}^{\theta^{l}}, \frac{y^{\theta^{l}}}{\theta^{l}}\right)}<\frac{U_{c_{1}}\left(c_{1}^{\theta^{l}}, c_{2}^{\theta^{l}}, \frac{y^{\theta^{l}}}{\theta^{h}}\right)}{U_{c_{2}}\left(c_{1}^{\theta^{l}}, c_{2}^{\theta^{l}}, \frac{y^{\theta^{l}}}{\theta^{l}}\right)} .
$$

If $y^{\theta^{l}}>0$, the labor supply of an honest low type, $\frac{y^{\theta^{l}}}{\theta^{l}}$, will be higher ${ }_{y^{l}}$ than the labor supply of a high type who reports a low value of $\theta$ to the planner, $\frac{y^{\theta^{l}}}{\theta^{h}}$. Thus Eq. (6) implies that if an increase in labor supply tends to decrease the marginal utility of good 2 less than the marginal utility of good 1, then the optimal allocation will feature a positive distortion. More succinctly, the planner should tax good 1 relative to good 2 if good 1 is more complementary to leisure than good 2. This will harm a lying high type more than it will harm an honest low type because the lying high type supplies less labor and therefore enjoys more leisure. The distortion thus makes it easier to provide incentives, which in turn allows for more redistribution from high types to low types. This sort of motive is exactly what the weak separability condition of Atkinson and Stiglitz (1976) rules out, as separability ensures that no goods are relatively more complementary to leisure than others. Notice, though, that even without assuming weak separability, if $y^{\theta^{l}}=0$, then Eq. (5) cannot hold. This implies that, if in the optimal allocation low types supply no labor, then their consumption margin should not be distorted either. If low types don't work, then a true low type and a lying high type will consume the same amount of leisure, and there is no leverage to be gained against incentives by taxing complements to leisure. 


\section{A simple Mirrleesian model with home production}

The standard Mirrleesian model of the previous section cannot deliver distortions to consumption margins for an agent that is not working in the optimal allocation. This implies it cannot justify the in-kind benefits received by retirees and people on longterm disability under the U.S. social insurance system. To reiterate the analysis of Section 3, the reason for this is that consumption margins should only be distorted when honest agents and dishonest agents consume different amounts of leisure, in order to take advantage of differing degrees of complementarity. In this section, I will show that introducing home production in a simple Mirrleesian model can break down this result. The home production model is isomorphic to a Mirrleesian model with type-dependent preferences. The MRS can thus vary across types as in Saez (2002), even when agents do not work. This is true even if the underlying preferences of agents are additively separable, as I show in an example in Section 4.2.

\subsection{Model}

There are again two productivity types: $\theta^{h}$ (high type) and $\theta^{l}$ (low type). Each productivity type $\theta$ has two separate labor productivities: one for market production $\theta_{1}$ and one for home production $\theta_{2}$. I will make the following assumption.

Assumption $1 \theta_{1}^{h}>\theta_{1}^{l}$ and $\theta_{2}^{h}>\theta_{2}^{l}$, i.e. home and market productivity are positively correlated and high $\theta$ types are better at both home and market production.

The assumption of positive correlation of home and market productivities is important for the theoretical results to follow in Section 4.2 and merits some discussion. When type variation is the result of gender differences, it is likely not reasonable to assume positive correlation of home and market productivities. In a study of time spent cooking, Etile and Plessz (2018), for instance, documented that women in France on average had lower wages than men (hence lower $\theta_{1}$ ) and were inherently more productive at home cooking (hence higher $\theta_{2}$ ). ${ }^{4}$ However, the focus of this paper is accounting for in-kind welfare benefits given to retirees and the disabled. In these two populations, it is likely that a key force underlying differences in productivity against which the government is trying to provide insurance is health. In particular, we expect low types to be less healthy than high types. The validity of Assumption 1 for the purposes of this analysis then hinges on whether healthy agents are more productive both in the home and in the market than unhealthy agents. Turning to the market first, there is a large empirical literature that examines the impact of health status on wages (see, e.g., Currie and Madrian (1999) for a good survey). The general finding of this literature is that improved health tends to increase wages. Taking wages as a proxy for market productivity, this suggests that healthy agents are indeed more productive in the market. In terms of home productivity, Podor and Halliday (2012) use ATUS and HRS data to study the connection between

\footnotetext{
${ }^{4}$ Etile and Plessz (2018) show that women's cooking time was largely independent of spouse earnings, which they took as evidence of the insubstitutability of women's labor in home cooking. They were agnostic on the source of insubstitutability, be it societal pressure on women to cook, intrinsic productivity differences between men and women or both. A high $\theta_{2}$ could proxy for either.
} 
health, consumption, and the allocation of time. Their key findings for the purposes of this paper are: (1) Time spent in home production tends to increase with health status $^{5}$ and (2) Spending on goods that are close substitutes for home production activity (such as housekeeping and lawn care services) tends to decrease with health status. This suggests that healthier people substitute time spent in home production for market consumption, in spite of facing a higher opportunity cost of time than less healthy people due to higher wages. This in turn would suggest that healthier people are also more productive when allocating time to home production.

Continuing with the exposition of the model, there is a single market output good $y$. An agent with type $\theta$ produces $y$ with market labor $l_{1}^{\theta}$ according to $y=\theta_{1} \times l_{1}^{\theta} \cdot y$ can be transformed one for one into two consumption goods: $c_{1}$ and $c_{2}$. $c_{1}$ is consumed directly by agents. Agents combine home labor $l_{2}^{\theta}$ and $c_{2}$ to produce a home good $c_{h}$ according to $c_{h}=f\left(c_{1}, \theta_{2} \times l_{2}^{\theta}\right)$. Conceptually, $c_{1}$ represents goods such as restaurant meals which require little or no preparation for final consumption. $c_{2}$ represents goods such as groceries which an agent must first spend time preparing before consuming. Preferences are represented by the utility function $v\left(c_{1}, c_{h}, l_{1}, l_{2}\right)$. Market output $y$, and consumption of the market goods $c_{1}$ and $c_{2}$ are observable to the planner. Home production and productivity are not. It is convenient to define type dependent indirect utility functions over market quantities

$$
u^{\theta}\left(c_{1}, c_{2}, l_{1}\right)=\max _{l_{2}} v\left(c_{1}, f\left(c_{2}, \theta_{2} \times l_{2}\right), l_{1}, l_{2}\right) .
$$

It follows from the envelope theorem that the marginal rate of substitution between $c_{1}$ and $c_{2}$ for the indirect utility function is given by

$$
\frac{u_{c_{1}}^{\theta}}{u_{c_{2}}^{\theta}}=\frac{v_{c_{1}}}{v_{c_{h}} f_{c_{2}}} .
$$

Note that the marginal rate of substitution between these two consumption goods in the indirect utility function depends not only on the arguments of the indirect utility function $\left(c_{1}, c_{2}\right.$, and $\left.l_{1}\right)$, but also on type $\theta$. In general, agents of different types will choose different levels of home production labor $l_{2}$ and home production effective labor $\theta_{2} \times l_{2}$. This will cause variation in the arguments of the home production function $f$ and the underlying utility function $v$ across types, which in turn will translate into cross-type variation of the right hand side of Eq. (8). Type dependence of the MRS is crucial to the results that follow.

The utilitarian planner's problem can be formulated in terms of the indirect utility functions. As with the standard Mirrleesian model of Section 3, applying the revelation principle, substituting market output divided by productivity for market labor, and assuming that only the incentive constraint of the high type is binding allows the

\footnotetext{
5 Pentland et al. (1999) document a similar time use pattern in disabled men with spinal injuries.
} 
planner's problem to be formulated as

$$
\begin{aligned}
& \max _{c_{1}^{\theta^{l}}, c_{2}^{\theta^{l}}, y^{\theta^{l}}, c_{1}^{\theta^{h}}, c_{2}^{\theta^{h}, \theta^{\theta^{h}}}} \pi u^{\theta^{l}}\left(c_{1}^{\theta^{l}}, c_{2}^{\theta^{l}}, \frac{y^{\theta^{l}}}{\theta_{1}^{l}}\right)+(1-\pi) u^{\theta^{h}}\left(c_{1}^{\theta^{h}}, c_{2}^{\theta^{h}}, \frac{y^{\theta^{h}}}{\theta_{1}^{h}}\right) \\
& \text { s.t. } \pi\left[c_{1}^{\theta^{l}}+c_{2}^{\theta^{l}}\right]+(1-\pi)\left[c_{1}^{\theta^{h}}+c_{2}^{\theta^{h}}\right]=\pi y^{\theta^{l}}+(1-\pi) y^{\theta^{h}} \\
& u^{\theta^{h}}\left(c_{1}^{\theta^{h}}, c_{2}^{\theta^{h}}, \frac{y^{\theta^{h}}}{\theta_{1}^{h}}\right) \geq u^{\theta^{h}}\left(c_{1}^{\theta^{l}}, c_{2}^{\theta^{l}}, \frac{y^{\theta^{l}}}{\theta_{1}^{h}}\right)
\end{aligned} .
$$

The first constraint of the planner's problem again represents resource feasibility and the second is an incentive constraint that imposes truthful revelation of high types. Similar to the model in Section 3, it can be shown through first order conditions that the MRS between $c_{1}$ and $c_{2}$ for the high $\theta$ type in the optimal allocation will satisfy

$$
\frac{u_{c_{1}}^{\theta^{h}}\left(\theta^{h}\right)}{u_{c_{2}}^{\theta^{h}}\left(\theta^{h}\right)}=1
$$

For the low $\theta$ type it will satisfy

$$
\frac{u_{c_{1}}^{\theta^{l}}\left(\theta^{l}\right)}{u_{c_{1}}^{\theta^{l}}\left(\theta^{l}\right)}=\frac{1-\frac{\mu}{\pi} \frac{u_{c_{2}}^{\theta^{l}}\left(c_{1}^{\theta_{1}^{l}}, c_{2}^{\theta^{l}}, \frac{\theta^{\theta^{l}}}{\theta_{1}^{l}}\right)}{u_{c_{2}}^{\theta^{l}}\left(\theta^{l}\right)}}{1-\frac{\mu}{\pi} \frac{u_{c_{1}}^{\theta^{h}}\left(c_{1}^{\theta^{l}}, c_{2}^{\theta^{l}}, \frac{\theta^{l}}{\theta_{1}^{l}}\right)}{u_{c_{1}}^{\theta^{l}}\left(\theta^{l}\right)}} .
$$

Here $\mu$ is the Lagrange multiplier on the incentive constraint from the planner's problem. Again, Eq. (10) implies the consumption margin will not be distorted for high types in an optimal allocation, and, by Eq. (11), that of the low type will be distorted if and only if

$$
\frac{u_{c_{1}}^{\theta^{l}}\left(\theta^{l}\right)}{u_{c_{2}}^{\theta^{l}}\left(\theta^{l}\right)} \neq \frac{u_{c_{1}}^{\theta^{h}}\left(c_{1}^{\theta^{l}}, c_{2}^{\theta^{l}}, \frac{y^{\theta^{l}}}{\theta_{1}^{h}}\right)}{u_{c_{2}}^{\theta^{h}}\left(c_{1}^{\theta^{l}}, c_{2}^{\theta^{l}}, \frac{y^{\theta^{l}}}{\theta_{1}^{h}}\right)} .
$$

Notice that the functions on the left and the right hand side of Eq. (12) are no longer identical, as they were in Eq. (5). This implies that the inequality can hold even if the arguments of the functions on the left and right hand side are identical. The result of Section 3 no longer necessarily goes through. In what follows, I will give an example of functional forms of the underlying utility function $v$ and the home production function $f$ where it explicitly does not.

\subsection{Example for home production model}

Suppose that the utility function $v\left(c_{1}, c_{h}, l_{1}, l_{2}\right)$ has the form

$$
v\left(c_{1}, c_{h}, l_{1}, l_{2}\right)=\log \left(c_{1}\right)+\log \left(c_{h}\right)-\alpha\left(l_{1}+l_{2}\right),
$$


where $\alpha>0$ is a constant, and the home production function $f$ has the form

$$
f\left(c_{2}, \theta_{2} \times l_{2}\right)=\left\{\gamma c_{2}^{\frac{\sigma-1}{\sigma}}+(1-\gamma)\left(\theta_{2} \times l_{2}\right)^{\frac{\sigma-1}{\sigma}}\right\}^{\frac{\sigma}{\sigma-1}},
$$

where $\gamma \in(0,1)$ and $\sigma>0$. With these preferences, for a given quantity of $c_{2}$, an agent of type $\theta$ will choose time spent in home production to satisfy the first order condition

$$
\frac{(1-\gamma)\left(\theta_{2} l_{2}\right)^{\frac{\sigma-1}{\sigma}}}{\gamma c_{2}^{\frac{\sigma-1}{\sigma}}+(1-\gamma)\left(\theta_{2} l_{2}\right)^{\frac{\sigma-1}{\sigma}}} \times \frac{1}{l_{2}}=\alpha .
$$

This first-order condition leads to the following proposition:

Proposition 1 Let $l_{2}\left(\theta_{2}\right)$ denote the solution to (13) as a function of the home labor productivity parameter $\theta_{2}$. Then $\theta_{2} \times l_{h}\left(\theta_{2}\right)$ is increasing in $\theta_{2}$ for $\theta_{2}>0$.

\section{Proof. See Appendix.}

Proposition 1, along with assumption 1, establishes that, in the optimal allocation that solves the planner's problem Eq. (9), a high type who claims to be a low type will choose to supply more effective labor in home production than an honest low type. As in the standard Mirrleesian model of Section 3, the consumption margin between final goods $c_{1}$ and and intermediate consumption goods $c_{2}$ for the low type in the optimal allocation will satisfy

$$
\frac{u_{c_{1}}^{\theta^{l}}\left(\theta^{l}\right)}{u_{c_{2}}^{\theta^{l}}\left(\theta^{l}\right)} \gtrless 1 \Longleftrightarrow \frac{u_{c_{1}}^{\theta^{l}}\left(\theta^{l}\right)}{u_{c_{2}}^{\theta^{l}}\left(\theta^{l}\right)} \lessgtr \frac{u_{c_{1}}^{\theta^{h}}\left(c_{1}^{\theta^{l}}, c_{2}^{\theta^{l}}, \frac{y^{\theta^{l}}}{\theta_{1}^{l}}\right)}{u_{c_{2}}^{\theta^{h}}\left(c_{1}^{\theta^{l}}, c_{2}^{\theta^{l}}, \frac{y^{\theta^{l}}}{\theta_{1}^{h}}\right)} .
$$

Then, by Eq. (8), this will hold if and only

$$
\frac{\gamma\left(c_{2}^{\theta^{\theta^{\prime}}}\right)^{\frac{\sigma-1}{\sigma}}+(1-\gamma)\left(\theta_{2}^{l} l_{2}\left(\theta_{2}^{l}\right)\right)^{\frac{\sigma-1}{\sigma}}}{c_{1}^{\theta^{l}}} \times\left(c_{2}^{\theta^{l}}\right)^{\frac{1}{\sigma}} \lessgtr \frac{\gamma\left(c_{2}^{\theta^{l}}\right)^{\frac{\sigma-1}{\sigma}}+(1-\gamma)\left(\theta_{2}^{h} l_{2}\left(\theta_{2}^{h}\right)\right)^{\frac{\sigma-1}{\sigma}}}{c_{1}^{\theta^{l}}} \times\left(c_{2}^{\theta^{l}}\right)^{\frac{1}{\sigma}} .
$$

Here, $l_{2}\left(\theta_{2}\right)$ again denotes the solution to the home production optimality condition Eq. (13). Finally, as per Proposition $1, \theta_{2}^{h} \times l_{2}\left(\theta_{2}^{h}\right)>\theta_{2}^{l} l_{2}\left(\theta_{2}^{l}\right)$, hence this will be satisfied if and only if $\sigma \gtrless 1$. Summing up, in the optimal allocation

$$
\frac{u_{c_{1}}^{\theta^{l}}\left(\theta^{l}\right)}{u_{c_{2}}^{\theta^{l}}\left(\theta^{l}\right)} \gtrless 1 \Longleftrightarrow \sigma \gtrless 1 \text {. }
$$

The parameter $\sigma$ is the elasticity of technical substitution between goods and effective labor in home production. Goods are substitutes for labor in production if $\sigma>1$ and complements if $\sigma<1$. The interpretation of this condition is that high types in essence have more labor to use in home production because of their higher productivity. A tax on goods for home production aimed at low types will thus be more painful for high types than for low types if goods are complements to labor in production and is an efficient way to provide incentives. A subsidy on goods for home production aimed at low types will be more beneficial for low types than for dishonest high types if goods are substitutes for labor in production, and thus provides a cheap way of 
increasing the utility of low types. Notice, though, that the analysis above in no way depends on $y^{\theta^{l}}$. The sign of the distortion to the MRS of low types is determined entirely by $\sigma$. Hence even if $y^{\theta^{l}}=0$ in the optimal allocation and the low type does not work in the market, there will be either marginal taxation or subsidization of intermediate goods for home production relative to final goods. A Mirrleesian model with home production can thus provide an efficiency reason for in-kind welfare benefits during retirement and periods of disability.

\subsection{Empirical evidence}

The results of the home production model suggest that a social insurance system should provide goods used intensively in home production in-kind if goods and labor are substitutes in home production. Is this consistent with the form of in-kind benefits and empirical evidence on home production in the U.S.? Turning first to the provision of goods, Fig. 1 gives data on the scale of various in-kind benefits provided by the U.S. government in 2015.

This graph divides in-kind programs into the five broad categories presented in the U.S. House of Representatives Ways and Means Committee's Green Book: education, healthcare, home energy assistance, housing assistance, and nutrition assistance. ${ }^{6}$ Combined, spending on all such programs accounts for approximately $13 \%$ of GDP. Turning to the individual program categories in the graph, the model presented in this paper is not applicable to spending on public education or healthcare. Although one could plausibly argue that improving a person's health or offering them educational services should lead to higher output in home production, the effects of education and healthcare have traditionally been modeled as increasing labor productivity through human capital accumulation. This would correspond to increasing the output of home production by increasing $\theta_{2}$ rather than $c_{2}$. As the model takes productivity as exogenous, these effects are not captured. Of the three remaining program categories, all cover programs that provide goods used intensively in home production: groceries, housing capital, and home energy. ${ }^{7}$

Turning next to the home production technology, several studies report that goods and labor are substitutes in home production. Using scanner data and the ATUS, Aguiar and Hurst (2007) find an elasticity of substitution between goods and labor of 1.8. McGrattan et al. (1997) find a similar value of $1.75 .^{8}$ The substitutability of goods and labor in home production and the goods provided in-kind by the U.S. social safety net are consistent with the use of in-kind benefits to incentivize labor supply, based on the results of Section 4.2. In order to make a sharper statement on the intent of the in-kind provision of goods for home production in the U.S. social

\footnotetext{
${ }^{6}$ Education and job training are combined in this graph, although job training is very small relative to public education spending.

7 While nutrition assistance includes programs that provide both prepared meals, such as school lunch programs, and food that would be used directly in home production, such as SNAP, by far the largest program providing nutrition assistance is SNAP, which represents about three quarters of all nutrition assistance.

8 This is the value implied by setting the factor intensity of capital equal to 0 in home production. In this case, their model reduces to a special case of the one presented in Section 4, where market consumption goods do not enter the utility function, i.e. all consumption goods are used in home production.
} 
safety net, I next conduct a simulation using the model of Section 4.2 to compute the size of the optimal in-kind welfare benefit for disabled workers to compare with the scale of the programs in Fig. 1.

\subsection{Simulation}

Due to the qualitative empirical evidence on home production and the form of inkind benefits provided in the U.S., it is of interest to use to the model of Section 4.2 to examine the provision of in-kind benefits to non-working households quantitatively. In order to do that, we must first choose parameters for the model. First, the value of market and home productivity of high types $\theta_{1}^{h}$ and $\theta_{2}^{h}$ are both normalized to one. Next, to model disability, the market productivity of low types $\theta_{1}^{l}$ is set to zero. The home productivity of low types $\theta_{2}^{l}$ is set equal to 0.5 in the baseline version of the model and allowed to vary in sensitivity analysis. The proportion of the population that is a low type $\pi$ is taken from BLS data on the fraction of the working age population with a disability and is set to 0.09 . The factor intensity of goods in home production $\gamma$ is taken from McGrattan et al. (1997) and is set equal to 0.4. ${ }^{9}$

The elasticity of technical substitution $\sigma$ is taken from Aguiar and Hurst (2007) and is set equal to 1.45 . This is lowest value they report. I favor this value because in their model, they assume that all consumption goods are used in home production, whereas mine assumes that only a subset of goods are used in home production. This assumption runs the risk of making it appear that households that reduce home production labor and buy market goods are substituting goods for labor in home production when they are, in fact, substituting market goods for goods produced at home. This potentially overstates the substitutability of goods and labor in home production. Finally, the disutility of labor $\alpha$ is set to 4.67 , so that in the baseline version of the model high productivity types spend $30 \%$ of their available time supplying market labor, consistent with the hours data of Cociuba et al. (2018).

In order to decentralize the constrained efficient allocation that solves the planner's problem using using a non-linear income tax, a cash benefit and an in-kind benefit, the government could simply provide the value of the low type's consumption of the market intermediate good $c_{2}$ in-kind and a cash benefit equal to the low type's consumption of the market final good $c_{1}$ to any household with a sufficiently low income ( 0 in this case) and finance it with an appropriate income tax paid by high types. ${ }^{10}$ The scale of the required in-kind benefits as a fraction of GDP could be computed by dividing the size $c_{2}^{\theta^{l}}$ by model GDP. In the baseline version of the model, with $\theta_{2}^{l}=0.5$, the in-kind program accounts for $1 \%$ of GDP. This decreases to $0.78 \%$ of GDP for $\theta_{2}^{l}=0.8$. The effects of varying $\theta_{2}^{l}$ are shown in Fig. 2 .

The scale of the optimal in-kind program is decreasing in $\theta_{2}^{l}$. Intuitively, as $\theta_{2}^{l}$ increases, the gap between the home productivity of low types and high types narrows. This causes honest low types and dishonest high types to value the intermediate good $c_{2}$ more similarly, which reduces the ability of offering that good as an in-kind

\footnotetext{
${ }_{9}$ Again, this is the value implied by setting the factor intensity of capital in home production equal to zero in their model.

${ }^{10}$ This decentralization works because $c_{2}$ is effectively subsidized for the low type in the optimal allocation, as the results of Section 4.2 and the value of $\sigma$ imply.
} 


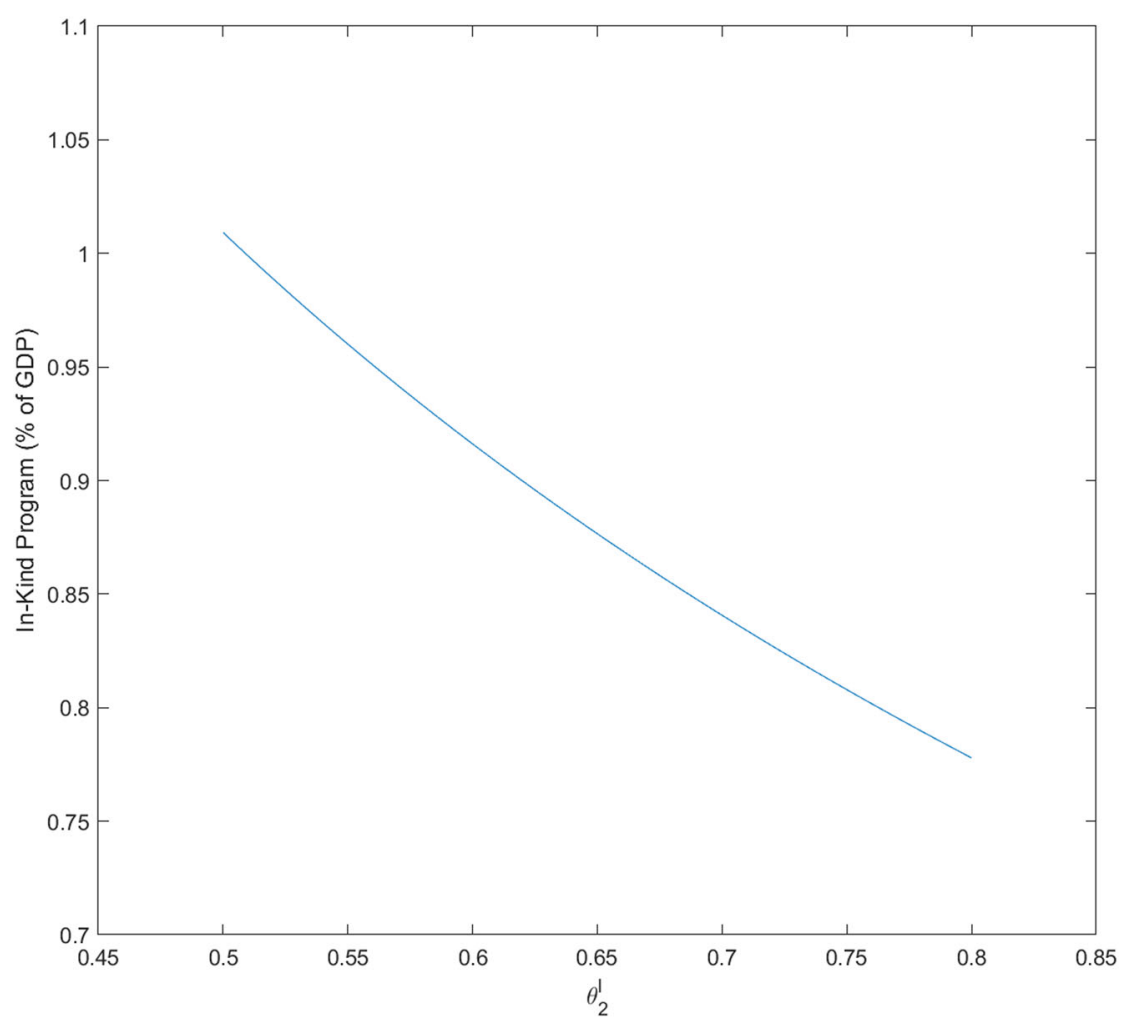

Fig. 2 Effects of varying on in-kind welfare benefits. $\theta_{2}^{l}$ is the home labor productivity of low types. As $\theta_{2}^{l}$ increases, the difference in the valuation of intermediate goods $c_{2}$ by honest low types and dishonest high types shrinks, decreasing the ability of in-kind benefits to slacken the incentive constraint of the planner's problem and leading to smaller optimal in-kind benefit programs

benefit the slacken the incentive constraint in the planner's problem. Consequently, the planner reduces the scale of the in-kind program. As shown in Fig. 1, in the U.S. spending on in-kind welfare benefits that provide goods used in home production accounts for approximately $0.9 \%$ of GDP. This includes benefits for the disabled as well as able-bodied households. Per the USDA, approximately $20 \%$ of households receiving SNAP benefits have a disabled head of household. If enrollment of the disabled in other in-kind home production goods programs is comparable, this would suggest that spending on in-kind home production benefits for the disabled is equal to $0.18 \%$ of GDP. This figure is comparable in scale to the in-kind benefit program that decentralizes the solution to the planner's problem in the simulation for all values of $\theta_{2}^{l}$, although it is slightly smaller. This is suggestive that efficiency of the U.S. social safety net could be improved by expanding in-kind aid to the disabled. 


\section{Conclusion}

The provision of in-kind benefits is a large component of the U.S. social safety net. Spending on such programs is equal to just over $13 \%$ of GDP. ${ }^{11}$ These programs effectively subsidize the goods they provide. It is unclear why such subsidization would be desirable from the government's perspective. The implicit subsidies will restrict and distort the behavior of people that receive benefits, leading to a potential efficiency loss relative to giving the cash value of aid instead. Three arguments have been advanced to justify the use of in-kind benefits. The first, following Loury (1981), shows that public education programs can be an efficient response to borrowing constraints in human capital markets. The second, following Musgrave (1959), argues that in-kind benefits provide a way for a paternalistic government or society to impose its preferences on households in the social safety net. The third, following Atkinson and Stiglitz (1976), Nichols and Zeckhauser (1982), and Guesnerie and Roberts (1984), argues that providing benefits in-kind can be an efficient way to provide incentives that encourage households that do not need social insurance to supply labor and pay into the welfare system, thus allowing for more generous welfare programs for households that do need social insurance. One issue with this "incentives" argument in favor of in-kind benefits, conjectured by Currie and Gahvari (2008), is that in practice, a substantial fraction of inkind benefits are given to households that supply no labor in the market, either due to age or disability status. Such benefits seem inconsistent with incentivizing labor supply. This paper makes several contributions to this debate. First, it formalizes Currie and Gahvari (2008)'s conjecture by showing that, in a standard Mirrleesian optimal taxation framework, it is not efficient to offer in-kind benefits to agents that are not working. However, it also shows that this result is not robust to adding home production to the standard Mirrleesian framework. In a tractable version of the Mirrleesian home production model, I show that if household market labor and home labor productivities are positively correlated, and goods are substitutes for labor in home production, then it is efficient to offer goods used intensively in home production as an in-kind welfare benefit, even if low productivity households do not supply labor in the market. Such a program is consistent with empirical evidence on time use, home production technologies, and the form of many in-kind programs in the U.S., which provide goods used intensively in home production (e.g. groceries, housing capital, and home energy). I show in a numerical exercise that with plausible parameter values the scale of the optimal in-kind benefit program for disabled households is roughly consistent with the size of programs in the U.S. social safety net that provide goods used directly in home production.

While this paper establishes home production as a consideration for the design of inkind welfare programs, it leaves open many potential avenues of future research. First, it only considers home production in a static model. However, many of the non-working recipients of in-kind benefits in the U.S. are retirees. Moreover, as discussed in Aguiar and Hurst (2007), home production is crucial to understanding the behavior of households over the life cycle and particularly in retirement. It would therefore be of interest to extend the static home production model to a dynamic framework that could be used to analyze the optimal provision of in-kind benefits during retirement. As discussed in Section 4.3, the model cannot address in-kind programs designed to

11 See Fig. 1. 
increase human capital, such as public education or healthcare programs. However, such programs are the largest form of in-kind benefits in the U.S. and many other countries. Human capital accumulation should also have a direct impact on home production by increasing home labor productivity. These considerations could be addressed by adding human capital investment to the home production model and studying the conditions under which in-kind provision of human capital through education or healthcare is optimal and at what scale it should be provided. Finally, a limitation of the model presented in Section 4 is that it considers only single person households. However, as argued in Grossbard-Shechtman (2003), when goods are substitutable for labor in home production, married households may value home production intermediates significantly less than unmarried households, as they will effectively have more combined time to substitute for goods in home production. This suggests that home production intermediates could function as an indicator good, as in Nichols and Zeckhauser (1982), as household size will lead to variation in valuation. If the government had a reason to target welfare benefits at unmarried households, for instance to offer greater benefits to single parents, it could offer home production intermediates in-kind, similar to the programs discussed in Section 4. An extension of the model in this paper that included multi-person households could explore this incentive for in-kind benefits. As more production moves into the home due to the COVID-19 pandemic, and as economic crisis and demographic trends such as the retirement of the Baby Boomer generation expand the social safety net in both the shortrun and the long-run, the interplay between home production and optimal welfare design merits increased scholarly attention.

Acknowledgements I am deeply indebted to V.V. Chari, Larry Jones, and Chris Phelan for their continuous support and valuable advice. I would also like to thank Hengjie Ai, Manuel Amador, Alessandro Dovis, Zach Mahone, Juan Pablo Nicolini, Trevor O'Grady, Filippo Rebessi, Laura SunderPlassman, Don Vandegrift, two anonymous referees, and the members of the Chari Jones Phelan Workshop at the University of Minnesota for helpful comments. All remaining mistakes are my own.

\section{Compliance with ethical standards}

Conflict of interest The author declares no conflict of interest.

Publisher's note Springer Nature remains neutral with regard to jurisdictional claims in published maps and institutional affiliations.

\section{Appendix}

\subsection{Omitted proofs}

Proof of Proposition 1. Let $\theta_{2}^{1}>\theta_{2}^{2}>0$, and let $\tilde{l}_{2}\left(\theta_{2}^{1}\right)$ be such that $\theta_{2}^{1} \times \tilde{l}_{2}\left(\theta_{2}^{1}\right)=\theta_{2}^{2} l_{2}\left(\theta_{2}^{2}\right)$. Define the function

$$
\Phi\left(\theta_{2} \times l_{2}\right)=\frac{(1-\gamma)\left(\theta_{2} \times l_{2}\right)^{\frac{\sigma-1}{\sigma}}}{\gamma c_{2}^{\frac{\sigma-1}{\sigma}}+(1-\gamma)\left(\theta_{2} \times l_{2}\right)^{\frac{\sigma-1}{\sigma}}} .
$$


Notice that the left hand side of Eq. (13) can be written as

$$
\Phi\left(\theta_{2} l_{2}\right) \times \frac{1}{l_{2}} .
$$

Next, note that, because $\theta_{2}^{1}>\theta_{2}^{2}$, it follows that $\tilde{l}_{2}\left(\theta_{2}^{1}\right)<l_{2}\left(\theta_{2}\right)$. This implies that

$$
\Phi\left(\theta_{2}^{1} \tilde{l}_{2}\left(\theta_{2}^{1}\right)\right) \frac{1}{\tilde{l}_{2}\left(\theta_{2}^{1}\right)}=\Phi\left(\theta_{2}^{2} l_{2}\left(\theta_{2}^{2}\right)\right) \frac{1}{\tilde{l}_{2}\left(\theta_{2}^{1}\right)}>\Phi\left(\theta_{2}^{2} l_{2}\left(\theta_{2}^{2}\right)\right) \frac{1}{l_{2}\left(\theta_{2}^{2}\right)}=\alpha .
$$

Here, the first equality follows from the definition of $\tilde{l}_{2}\left(\theta_{2}^{1}\right)$ and the second equality from the definition of $l_{2}\left(\theta_{2}^{2}\right)$. Note next that the left hand side of Eq. (13) is decreasing in $l_{2}$ (this follows immediately from the concavity of the natural log and the CES production function $f$ ). Then given that

$$
\Phi\left(\theta_{2}^{1} \tilde{l}_{2}\left(\theta_{2}^{1}\right)\right) \frac{1}{\tilde{l}_{2}\left(\theta_{2}^{1}\right)}>\alpha
$$

it must be the case that $l_{2}\left(\theta_{2}^{1}\right)>\tilde{l}_{2}\left(\theta_{2}^{1}\right)$, hence

$$
\theta_{2}^{1} l_{h}\left(\theta_{2}^{1}\right)>\theta_{2}^{1} \tilde{l}_{h}\left(\theta_{2}^{1}\right)=\theta_{2}^{2} l_{2}\left(\theta_{2}^{2}\right)
$$

Then because $\theta_{2}^{1}$ and $\theta_{2}^{2}$ were arbitrary, this completes the proof.

\subsection{A general Mirleesian life cycle model}

Section 3 of the paper presented a simple, static model to provide some intuition for why, in an optimal allocation, consumption margins should not be distorted for agents that do not work. This section extends that result to a richer dynamic model that can address periods of labor market inactivity over the life cycle such as retirement or temporary or permanent disability. In particular, I will show that, in the absence of very strong time inseparability in preferences, in any period in which an agent does not work, his consumption margins should not be distorted in an optimal allocation.

\subsubsection{Environment}

Time is discrete and finite, indexed by $t=0, \ldots, T$. The economy is populated by a continuum of ex ante identical agents with mass 1 who work to produce output and consume. In each period $t$, each agent receives a labor productivity shock $\theta_{t}$. An agent with labor productivity $\theta_{t}$ can use labor input $l_{t}$ to produce output $y_{t}$ according to the linear technology $y_{t}=\theta_{t} l_{t}$. $\theta_{t}$ follows a Markov process with conditional distribution $F_{t}\left(\theta_{t} \mid \theta_{t-1}\right)$ (all agents have a common seed value $\theta_{-1}$ for the process) and support $[\underline{\theta}, \bar{\theta}]$ that does not vary with time. $\theta_{t}$ is private information of the agent; however, output and consumption are publicly observable. In each period, output $y_{t}$ can be transformed one-for-one into $N$ consumption goods $\left\{c_{j t}\right\}_{j=1}^{N}$. Output can also be transfered across periods at a fixed interest rate $R$. Agents' preferences over labor 
and consumption are given by

$$
\mathbf{E}\left[U\left(c_{10}, \ldots, c_{N 0}, l_{0}, \ldots, c_{1 t}, \ldots, c_{N t}, l_{t}, \ldots, c_{1 T}, \ldots, c_{N T}, l_{T}\right)\right],
$$

where $U$ is strictly increasing in all consumption goods, strictly decreasing in all labor supplies, and is twice continuously differentiable.

\subsubsection{Planner's problem}

I will set up the Planner's problem in terms of choosing a direct revelation mechanism to minimize the time 0 resource cost of providing a given utility level $\underline{U}{ }^{12}$ Let $\theta^{t}$ denote a $t$-length history of labor productivity shocks and $\Theta^{t}=[\underline{\theta}, \bar{\theta}]^{t}$ be the set of all possible t-length histories. An allocation rule is a set of functions $\left\{\left\{c_{j t}\right\}_{j=1}^{N}, y_{t}\right\}_{t=0}^{T}$ where $c_{j t}: \Theta^{t} \rightarrow \mathbb{R}_{+}$and $y_{t}: \Theta^{t} \rightarrow \mathbb{R}_{+}$are Borel measurable. A reporting strategy is a set of measurable functions $\left\{\sigma_{t}\right\}_{t=0}^{T}$ where $\sigma_{t}: \Theta^{t} \rightarrow[\underline{\theta}, \bar{\theta}]$. Any reporting strategy implies a set of reported history functions $\left\{\sigma^{t}\right\}_{t=0}^{T}$ where $\sigma^{t}$ : $\Theta^{t} \rightarrow \Theta^{t}$ is given by $\sigma^{t}\left(\theta^{t}\right)=\left(\sigma_{0}\left(\theta_{0}^{t}\right), \ldots, \sigma_{t}\left(\theta_{t}^{t}\right)\right)$. In what follows, I will ignore time subscripts where it will not cause confusion. Define an agent's utility from an allocation rule $\left\{\left\{c_{j}\right\}, y\right\}$ as

$$
U\left(\left\{\left\{c_{j}\right\}, y\right\}\right)=\mathbf{E}\left[U\left(c_{10}\left(\theta^{0}\right), \ldots, c_{N 0}\left(\theta^{0}\right), \frac{y_{0}\left(\theta^{0}\right)}{\theta_{0}}, \ldots, c_{1 T}\left(\theta^{T}\right), \ldots, c_{N T}\left(\theta^{T}\right), \frac{y_{T}\left(\theta^{T}\right)}{\theta_{T}}\right) \mid \theta_{-1}\right],
$$

and an agent's utility from a reporting strategy $\sigma$ given an allocation rule $\left\{\left\{c_{j}\right\}, y\right\}$ as

$$
\begin{aligned}
& U^{\sigma}\left(\left\{\left\{c_{j}\right\}, y\right\}\right)=\mathbf{E}\left[U \left(c_{10}\left(\sigma^{0}\left(\theta^{0}\right)\right), \ldots, c_{N 0}\left(\sigma^{0}\left(\theta^{0}\right)\right), \frac{y_{0}\left(\sigma^{0}\left(\theta^{0}\right)\right)}{\theta_{0}}, \ldots\right.\right. \\
& \left.\left.c_{1 T}\left(\sigma^{T}\left(\theta^{T}\right)\right), \ldots c_{N T}\left(\sigma^{T}\left(\theta^{T}\right)\right), \frac{y_{T}\left(\sigma^{T}\left(\theta^{T}\right)\right)}{\theta_{T}}\right) \mid \theta_{-1}\right]
\end{aligned}
$$

An allocation rule is incentive compatible if $U\left(\left\{\left\{c_{j}\right\}, y\right\}\right) \geq U^{\sigma}\left(\left\{\left\{c_{j}\right\}, y\right\}\right) \forall \sigma$ Note that if $\sigma$ is the truthful reporting strategy (i.e. $\left.\sigma_{t}\left(\theta^{t}\right)=\theta_{t}\right)$, then $U\left(\left\{\left\{c_{j}\right\}, y\right\}\right)=U^{\sigma}$ $\left(\left\{\left\{c_{j}\right\}, y\right\}\right)$, thus this requires the optimality of truth telling. Finally, an allocation rule satisfies promise keeping if

$$
U\left(\left\{\left\{c_{j}\right\}, y\right\}\right) \geq \underline{U} .
$$

I can now formulate the planner's problem, which is given by

$$
\begin{aligned}
& \min _{\left\{\left\{c_{j}\right\}, y\right\}} \sum_{t=0}^{T} R^{-t} \int_{\underline{\theta}}^{\bar{\theta}} \ldots \int_{\underline{\theta}}^{\bar{\theta}}\left(\sum_{j=1}^{N} c_{j t}\left(\theta^{t}\right)-y_{t}\left(\theta^{t}\right)\right) d F_{t}\left(\theta_{t} \mid \theta_{t-1}\right) \ldots d F_{0}\left(\theta_{0} \mid \theta_{-1}\right) \\
& \text { s.t. } U\left(\left\{\left\{c_{j}\right\}, y\right\}\right) \geq \underline{U} \\
& U\left(\left\{\left\{c_{j}\right\}, y\right\}\right) \geq U^{\sigma}\left(\left\{\left\{c_{j}\right\}, y\right\}\right) \forall \sigma
\end{aligned}
$$

\footnotetext{
12 This sort of partial equilibrium analysis is a common approach to characterizing allocations in the optimal taxation literature, see e.g. Farhi (2013). One interpretation is that the planner represents a government that is financing social insurance for a single cohort in part with distortionary taxes imposed on other cohorts or in other sectors of the economy. In order to minimize the impact of these distortions, the government would want to minimize the amount of revenue they must raise.
} 
Assumption 2 The expected utility function $U$ is weakly time separable, i.e. $\exists$ realvalued functions $\left\{G_{t}\right\}_{t=0}^{T}$ and $V$ s.t.

$$
U\left(c_{10}, \ldots, c_{N 0}, l_{0}, \ldots, c_{1 T}, \ldots, c_{N T}, l_{T}\right)=V\left(G_{0}\left(c_{10}, \ldots, c_{N 0}, l_{0}\right), \ldots, G_{T}\left(c_{1 T}, \ldots, c_{N T}, l_{T}\right)\right) .
$$

Notice that Assumption 2 is satisfied by recursive prefernces such as Epstein Zin as well as by more conventional utility functions that are additively separable in time. I can now state the main result of Appendix 6.2.

Theorem 1 Suppose Assumption 2 holds and $\left\{\left\{c_{j}^{*}\right\}, y^{*}\right\}$ is a solution to Eq. (15). Then for almost every history ${ }^{13} \theta^{t}$ s.t. $y_{t}^{*}\left(\theta^{t}\right)=0$ consumption margins are not distorted in $\theta^{t}$, i.e.

$$
\frac{G_{t, i}\left(\theta^{t}\right)}{G_{t, j}\left(\theta^{t}\right)}=1 \forall i, j \in\{1, \ldots, N\} .
$$

Proof. Let $\left\{\left\{c_{j}^{*}\right\}, y^{*}\right\}$ be an allocation rule that solves Eq. (15). For simplicity and clarity, I will consider a single history $\theta^{t}$ with positive mass and $y_{t}^{*}\left(\theta^{t}\right)=0$. This argument can easily be extended to a set of such histories with positive mass by applying the following argument to all histories in the set. Consider the following minimization problem

$$
\min _{\left\{c_{j}\right\}} \sum_{j=1}^{N} c_{j} \text { s.t. } G_{t}\left(c_{1}, \ldots, c_{N}, 0\right)=G_{t}\left(c_{1 t}^{*}\left(\theta^{t}\right), \ldots, c_{N t}^{*}\left(\theta^{t}\right), 0\right) .
$$

Let $\left\{c_{j}\right\}$ be any consumption bundle that satisfies the constraints of Eq. (16). Define an allocation rule $\left\{\left\{\hat{c}_{j}\right\}, \hat{y}\right\}$ as follows

$$
\hat{y}\left(\theta^{s}\right)=y^{*}\left(\theta^{s}\right) \hat{c}_{j s}\left(\theta^{s}\right)= \begin{cases}c_{j s}^{*}\left(\theta^{s}\right) & \theta^{s} \neq \theta^{t} \\ c_{j} & \theta^{s}=\theta^{t}\end{cases}
$$

Notice that if we can show that the allocation rule $\left\{\left\{\hat{c}_{j}\right\}, \hat{y}\right\}$ satisfies the constraints of Eq. (15), it would follow that $\left\{c_{j t}^{*}\left(\theta^{t}\right)\right\}$ must solve Eq. (16) (otherwise, it would be possible to construct an alternative allocation to the solution to Eq. (15) that was incentive compatible and satisfied voluntary participation, and used strictly less resources in history $\theta^{t}$, and hence lowered the planner's objective, namely $\left\{\left\{\hat{c}_{j}\right\}, \hat{y}\right\}$ ). To show this, let $\sigma$ be any reporting strategy, $\tilde{\theta}^{T}$ be any history of length $T$, and $\tilde{\theta}^{s}$

\footnotetext{
13 The distinction of "almost every history" is a technical one stemming from the assumption of continuous types in this model. This implies that the histories integrated over in the planner's problem are also continuous. If an allocation solved the planner's problem and satisfied the no-distortion condition of Theorem 1 on all histories in which agents do not work, the allocation could be altered in a subset of these histories with measure zero without changing the value of the objective of the planner's problem. As long as the adjustments were made in a way that maintained incentive compatibility, the alternative allocation, which did not satisfy the no-distortion result in all histories, just almost every history (because it is adjusted only on a set of histories with measure zero) would also be a solution to the planner's problem. This technicality could be dispensed with by assuming discrete types rather than continuous types.
} 
denote an $s$-length sub-history of $\tilde{\theta}^{T}$. Observe that, by the construction of $\left\{\left\{\hat{c}_{j}\right\}, \hat{y}\right\}$

$$
\begin{aligned}
& G_{s}\left(\hat{c}_{1 s}\left(\sigma^{s}\left(\tilde{\theta}^{s}\right)\right), \ldots, \hat{c}_{N s}\left(\sigma^{s}\left(\tilde{\theta}^{s}\right)\right), \frac{\hat{y}_{s}\left(\sigma^{s}\left(\tilde{\theta}^{s}\right)\right)}{\tilde{\theta}_{s}}\right) \\
& = \begin{cases}G_{s}\left(c_{1 s}^{*}\left(\sigma^{s}\left(\tilde{\theta}^{s}\right)\right), \ldots, c_{N s}^{*}\left(\sigma^{s}\left(\tilde{\theta}^{s}\right)\right), \frac{y_{s}^{*}\left(\sigma^{s}\left(\tilde{\theta}^{s}\right)\right)}{\tilde{\theta}_{s}}\right) & \sigma^{s}\left(\tilde{\theta}^{s}\right) \neq \theta^{t}, \\
G_{t}\left(c_{1}, \ldots, c_{N}, \frac{y^{*}\left(\sigma^{t}\left(\tilde{\theta}^{t}\right)\right)}{\tilde{\theta}_{t}}\right) & \sigma^{s}\left(\tilde{\theta}^{s}\right)=\theta^{t}\end{cases}
\end{aligned}
$$

and for this second case, we have

$$
\begin{aligned}
& G_{t}\left(c_{1}, \ldots, c_{N}, \frac{y_{t}^{*}\left(\sigma^{t}\left(\tilde{\theta}^{t}\right)\right)}{\tilde{\theta}_{t}}\right)=G_{t}\left(c_{1}, \ldots, c_{N}, 0\right) \\
& =G_{t}\left(c_{1 t}^{*}\left(\theta^{t}\right), \ldots, c_{N t}^{*}\left(\theta^{t}\right), 0\right) \\
& =G_{t}\left(c_{1 t}^{*}\left(\sigma^{t}\left(\tilde{\theta}^{t}\right)\right), \ldots, c_{N t}^{*}\left(\sigma^{t}\left(\tilde{\theta}^{t}\right)\right), \frac{y_{t}^{*}\left(\sigma^{t}\left(\tilde{\theta}^{t}\right)\right)}{\tilde{\theta}_{t}}\right)
\end{aligned} .
$$

Here, the second line follows from the fact that $\left\{c_{j}\right\}$ satisfies the constraint of Eq. (16) and the third line from the fact that $y_{t}^{*}\left(\theta^{t}\right)=0$. Hence, $\forall s$

$$
G_{s}\left(\hat{c}_{1 s}\left(\sigma^{s}\left(\tilde{\theta}^{s}\right)\right), \ldots, \hat{c}_{N s}\left(\sigma^{s}\left(\tilde{\theta}^{s}\right)\right), \frac{\hat{y}_{s}\left(\sigma^{s}\left(\tilde{\theta}^{s}\right)\right)}{\tilde{\theta}_{s}}\right)=G_{s}\left(c_{1 s}^{*}\left(\sigma^{s}\left(\tilde{\theta}^{s}\right)\right), \ldots, c_{N s}^{*}\left(\sigma^{s}\left(\tilde{\theta}^{s}\right)\right), \frac{y_{s}^{*}\left(\sigma^{s}\left(\tilde{\theta}^{s}\right)\right)}{\tilde{\theta}_{s}}\right) \text {. }
$$

Thus

$$
\begin{aligned}
& U\left(\hat{c}_{10}\left(\sigma^{0}\left(\tilde{\theta}^{0}\right)\right), \ldots, \hat{c}_{N 0}\left(\sigma^{0}\left(\tilde{\theta}^{0}\right)\right), \frac{\hat{y}_{0}\left(\sigma^{0}\left(\tilde{\theta}^{0}\right)\right)}{\tilde{\theta}_{0}}, \ldots\right. \\
& \left.\hat{c}_{1 T}\left(\sigma^{T}\left(\tilde{\theta}^{T}\right)\right), \ldots, \hat{c}_{N T}\left(\sigma^{T}\left(\tilde{\theta}^{T}\right)\right), \frac{\hat{y}_{T}\left(\sigma^{T}\left(\tilde{\theta}^{T}\right)\right)}{\tilde{\theta}_{T}}\right)= \\
& V\left(G_{0}\left(\hat{c}_{10}\left(\sigma^{0}\left(\tilde{\theta}^{0}\right)\right), \ldots, \hat{c}_{N 0}\left(\sigma^{0}\left(\tilde{\theta}^{0}\right)\right), \frac{\hat{y}_{0}\left(\sigma^{0}\left(\tilde{\theta}^{0}\right)\right)}{\tilde{\theta}_{0}}\right), \ldots\right. \\
& \left.G_{T}\left(\hat{c}_{1 T}\left(\sigma^{T}\left(\tilde{\theta}^{T}\right)\right), \ldots, \hat{c}_{N T}\left(\sigma^{T}\left(\tilde{\theta}^{T}\right)\right), \frac{\hat{y}_{T}\left(\sigma^{T}\left(\tilde{\theta}^{T}\right)\right)}{\tilde{\theta}_{T}}\right)\right)= \\
& V\left(G_{0}\left(c_{10}^{*}\left(\sigma^{0}\left(\tilde{\theta}^{0}\right)\right), \ldots, c_{N 0}^{*}\left(\sigma^{0}\left(\tilde{\theta}^{0}\right)\right), \frac{y_{0}^{*}\left(\sigma^{0}\left(\tilde{\theta}^{0}\right)\right)}{\tilde{\theta}_{0}}\right), \ldots\right. \\
& \left.G_{T}\left(c_{1 T}^{*}\left(\sigma^{T}\left(\tilde{\theta}^{T}\right)\right), \ldots, c_{N T}^{*}\left(\sigma^{T}\left(\tilde{\theta}^{T}\right)\right), \frac{y_{T}^{*}\left(\sigma^{T}\left(\tilde{\theta}^{T}\right)\right)}{\tilde{\theta}_{T}}\right)\right)= \\
& U\left(c_{10}^{*}\left(\sigma^{0}\left(\tilde{\theta}^{0}\right)\right), \ldots, c_{N 0}^{*}\left(\sigma^{0}\left(\tilde{\theta}^{0}\right)\right), \frac{y_{0}^{*}\left(\sigma^{0}\left(\tilde{\theta}^{0}\right)\right)}{\tilde{\theta}_{0}}, \ldots\right. \\
& \left.c_{1 T}^{*}\left(\sigma^{T}\left(\tilde{\theta}^{T}\right)\right), \ldots, c_{N T}^{*}\left(\sigma^{T}\left(\tilde{\theta}^{T}\right)\right), \frac{y_{T}^{*}\left(\sigma^{T}\left(\tilde{\theta}^{T}\right)\right)}{\tilde{\theta}_{T}}\right)
\end{aligned}
$$

Since the choice of $\tilde{\theta}^{T}$ was arbitrary, this relationship holds in expectation, implying

$$
U^{\sigma}\left(\left\{\left\{\hat{c}_{j}\right\}, \hat{y}\right\}\right)=U^{\sigma}\left(\left\{\left\{c_{j}^{*}\right\}, y\right\}\right),
$$

and since the choice of reporting strategies $\sigma$ was arbitrary, this holds for all $\sigma$. In particular, it holds for truth-telling, which implies

$$
U\left(\left\{\left\{\hat{c}_{j}\right\}, \hat{y}\right\}\right)=U\left(\left\{\left\{c_{j}^{*}\right\}, y^{*}\right\}\right) .
$$


Then, the fact that $\left\{\left\{c_{j}^{*}\right\}, y^{*}\right\}$ is a solution to Eqs. (15) and (18) implies that

$$
U\left(\left\{\left\{\hat{c}_{j}\right\}, \hat{y}\right\}\right)=U\left(\left\{\left\{c_{j}^{*}\right\}, y^{*}\right\}\right) \geq \underline{U},
$$

and hence $\left\{\left\{\hat{c}_{j}\right\}, \hat{y}\right\}$ satisfies promise keeping. Furthermore, since $\left\{\left\{c_{j}^{*}\right\}, y^{*}\right\}$ is a solution to Eqs. (15), (17) and (18) imply that

$$
U\left(\left\{\left\{\hat{c}_{j}\right\}, \hat{y}\right\}\right)=U\left(\left\{\left\{c_{j}^{*}\right\}, y^{*}\right\}\right) \geq U^{\sigma}\left(\left\{\left\{c_{j}^{*}\right\}, y\right\}\right)=U^{\sigma}\left(\left\{\left\{\hat{c}_{j}\right\}, \hat{y}\right\}\right) \forall \sigma,
$$

and hence $\left\{\left\{\hat{c}_{j}\right\}, \hat{y}\right\}$ satisfies incentive compatibility, thus $\left\{c_{j t}^{*}\left(\theta^{t}\right)\right\}$ must solve Eq. (16). Then, since $\left\{c_{j t}^{*}\left(\theta^{t}\right)\right\}$ is a solution to Eq. (16), $\left\{c_{j t}^{*}\left(\theta^{t}\right)\right\}$ must satisfy the first order conditions of Eq. (16). These first order conditions are given by

$$
1=\lambda G_{t j}\left(c_{1}, \ldots, c_{N}, 0\right)
$$

where $\lambda$ is the Lagrange multiplier associated with the equality constraint in Eq. (16). This in turn implies

$$
\frac{G_{t i}\left(c_{1}, \ldots, c_{N}, 0\right)}{G_{t j}\left(c_{1}, \ldots, c_{N}, 0\right)}=1 \forall i, j \in\{1, \ldots, N\} .
$$

Substituting $\left\{c_{j t}^{*}\left(\theta^{t}\right)\right\}$ above completes the proof.

This confirms the conjecture of Currie and Gahvari (2008): a standard Mirrleesian model (in the absence of highly non-standard preferences) does not provide an efficiency reason for distortions to consumption margins for agents that do not work.

\section{References}

Aguiar, M., \& Hurst, E. (2007). Life-cycle prices and production. American Economic Review, 97, $1533-1559$.

Atkinson, A. B., \& Stiglitz, J. E. (1976). The design of tax structure: direct versus indirect taxation. Journal of Public Economics, 6, 55-75.

Baland, J.-M., \& Robinson, J. A. (2000). Is child labor inefficient? Journal of Political Economy, 108, 663-679.

Bastani, S., Blomquist, S., \& Pirttilä, J. (2015). How should commodities be taxed? A counter-argument to the recommendation in the Mirrlees Review. Oxford Economic Papers, 67, 455-478.

Besley, T., \& Coate, S. (1991). Public provision of private goods and the redistribution of income. American Economic Review, 81, 979-984.

Blackorby, C., \& Donaldson, D. (1988). Cash versus kind, self-selection, and efficient transfers. American Economic Review, 78, 691-700.

Blomquist, S., \& Christiansen, V. (1995). Public provision of private goods as a redistributive device in an optimum income tax model. Scandinavian Journal of Economics, 97, 547-567.

Blömquist, S., \& Christiansen, V. (1998). Price subsidies versus public provision. International Tax and Public Finance, 5, 283-306.

Blomquist, S., \& Christiansen, V. (1998). Topping up or opting out? The optimal design of public provision schemes. International Economic Review, 39, 399-411.

Boadway, R., \& Marchand, M. (1995). The use of public expenditures for redistributive purposes. Oxford Economic Papers, 47, 45-59.

Campos, R. G., \& Reggio, I. (2016). Optimal unemployment insurance: consumption versus expenditure. Labour Economics, 38, 81-89.

Cociuba, S. E., Prescott, E. C., \& Ueberfeldt, A. (2018). US hours at work. Economics Letters, 169, 87-90.

Cremer, H., \& Gahvari, F. (1997). In-kind transfers, self-selection and optimal tax policy. European Economic Review, 41, 97-114.

Cremer, H., \& Gahvari, F. (1998). On optimal taxation of housing. Journal of Urban Economics, 43, 315-335. 
Currie, J., \& Gahvari, F. (2008). Transfers in cash and in-kind: theory meets the data. Journal of Economic Literature, 46, 333-383.

Currie, J., \& Madrian, B. C. (1999). Health, health insurance and the labor market. In O. Ashenfelter \& D. Card (Eds), Handbook of labor economics, vol 3, chapter 50 (pp. 3309-3416). Amsterdam: Elsevier.

daCosta, C. E. (2009). Yet another reason to tax goods. Review of Economic Dynamics, 12, 363-376.

Daruich, D. (2020). The macroeconomic consequences of early childhood development policies. Technical report, https://drive.google.com/file/d/0B5YmjVfr68oLbUlUMWI4clk4NXc/view?usp=sharing.

Dotsey, M., Li, W., \& Yang, F. (2015). Home production and social security reform. European Economic Review, 73, 131-150.

Etilé, F., \& Plessz, M. (2018). Womenas employment and the decline of home cooking: evidence from France, 1985-2010. Review of Economics of the Household, 16, 939-970.

Farhi, E. (2013). Insurance and taxation over the life cycle. Review of Economic Studies, 80, 596-635.

Gahvari, F. (1995). In-kind versus cash transfers in the presence of distortionary taxes. Economic Inquiry, $33,45-53$.

Gahvari, F., \& Mattos, E. (2007). Conditional cash transfers, public provision of private goods, and income redistribution. American Economic Review, 97, 491-502.

Gahvari, F., \& Micheletto, L. (2016). Capital income taxation and the Atkinson-Stiglitz theorem. Economics Letters, 147, 86-89.

Gasparini, L. C., \& Pinto, S. M. (2006). Equality of opportunity and optimal cash and in-kind policies. Journal of Public Economics, 90, 143-169.

Gnocchi, S., Hauser, D., \& Pappa, E. (2016). Housework and fiscal expansions. Journal of Monetary Economics, 79, 94-108.

Golosov, M., Kocherlakota, N., \& Tsyvinski, A. (2003). Optimal indirect and capital taxation. Review of Economic Studies, 70, 569-587.

Greenwood, J., \& Hercowitz, Z. (1991). The allocation of capital and time over the business cycle. Journal of Political Economy, 99, 1188-1214.

Grossbard-Shechtman, S. (2003). A consumer theory with competitive markets for work in marriage. Journal of Behavioral and Experimental Economics (Formerly The Journal of Socio-Economics), 31, 609-645.

Guesnerie, R., \& Roberts, K. (1984). Effective policy tools and quantity controls. Econometrica, 52, 59-86.

Kaplow, L. (2006). On the undesirability of commodity taxation even when income taxation is not optimal. Journal of Public Economics, 90, 1235-1250.

König, T., \& Lausen T. (2016). Relative consumption preferences and public provision of private goods. Discussion Papers SP II 2016-213, Research Unit: Market Behavior, WZB Berlin Social Science Center.

Loury, G. C. (1981). Intergenerational transfers and the distribution of earnings. Econometrica, 49, 843-867.

McGrattan, E. R., Rogerson, R., \& Wright, R. (1997). An equilibrium model of the business cycle with household production and fiscal policy. International Economic Review, 38, 267-290.

Mulligan, C. B., \& Philipson T. J. (2000). Merit motives and government intervention: public finance in reverse. University of Chicago, Stigler Center for Study of Economy and State. 159, https://ideas. repec.org/p/fth/chices/159.html.

Musgrave, R. A. (1959). The theory of public finance: a study in public economy. Amsterdam: McGraw Hill.

Nichols, A. L., \& Zeckhauser, R. J. (1982). Targeting transfers through restrictions on recipients. American Economic Review, 72, 372-377.

Olovsson, C. (2015). Optimal taxation with home production. Journal of Monetary Economics, 70, 39-50.

Pentland, W., Harvey, A. S., Smith, T., \& Walker, J. (1999). The impact of spinal cord injury on men's time use. Spinal Cord, 37, 786-792.

Pinto, S. M. (2004). Assistance to poor households when income is not observed: targeted in-kind and incash transfers. Journal of Urban Economics, 56, 536-553.

Podor, M., \& Halliday, T. J. (2012). Health status and the allocation of time. Health Economics, 21, 514-527.

Saez, E. (2002). The desirability of commodity taxation under non-linear income taxation and heterogeneous tastes. Journal of Public Economics, 83, 217-230.

Zhang, J., Davies, J., Zeng, J., \& McDonald, S. (2008). Optimal taxation in a growth model with public consumption and home production. Journal of Public Economics, 92, 885-896. 